\title{
Los sectores populares opositores a la vía chilena al socialismo. Notas para una discusión preliminar
}

\author{
Francisco Javier Morales ${ }^{1}$ \\ Recibido: 8 de agosto de 2015 - Aceptado: 10 de octubre de 2015
}

\begin{abstract}
Resumen
Los estudios sobre el periodo de la Unidad Popular han incorporado recién en los últimos años algunas temáticas novedosas sobre dicha experiencia, logrando de este modo sobrepasar la mirada esencialmente institucional del fenómeno. Sin embargo, algunos aspectos aún se encuentran ausentes del debate historiográfico. Este artículo plantea que las miradas sobre el mundo popular, elaboradas desde la academia y también desde la propia izquierda, se caracterizaron por su carácter globalizante y homogéneo, situación que impidió ver los matices, contradicciones y complejidades existentes en dicho espacio. Junto a la discusión teórica de rigor, se propone una reconstrucción y análisis de los principales elementos que configuraron y caracterizaron a la oposición popular al gobierno de Allende.
\end{abstract}

Palabras clave: Vía chilena al socialismo, oposición popular, teoría sobre movimientos sociales, Chile.

\section{Popular sectors opposite to chilean path to socialism. Notes for a preliminary discussion}

\begin{abstract}
Only in recent years, studies on the Unidad Popular times have incorporated some new themes on this experience, thereby surpassing the institutional look of the phenomenon. However, some aspects are still absent from the historiographical debate. This article argues that the look on the popular world, drawn from academia and from the left wind, was characterized by a globalizing and homogeneous nature, a situation that prevented from seeing the nuances, contradictions and complexities in that space. Along with the concrete theoretical discussion, it proposes a reconstruction and analysis of the main elements that informed and characterized the popular opposition to the Allende Government.
\end{abstract}

Keywords: Chilean socialism, popular opposition, theory of social movements 


\title{
Os setores populares antagonistas à vía chilena ao socialismo. Notas para uma discussão preliminar
}

\begin{abstract}
Resumo
0 estudo sobre o período da Unidade Popular tem incorporado recentemente nos últimos anos algumas temáticas inovadoras nesta experiência, conseguindo assim superar o olhar essencialmente institucional do fenômeno. No entanto, alguns aspectos ainda se encontram ausentes do debate historiográfico. Este artigo argumenta que os olhares sobre o mundo popular, provenientes desde a academia e também da própria esquerda, se caracterizaram pelo seu caráter globalizante e homogêneo, situação que impediu de ver as matizes, contradições e complexidades existentes nesse espaço. Junto com a discussão teórica de rigor, propõe-se uma reconstrução e análise dos principais elementos que configuraram e caracterizaram a oposição popular ao governo de Allende.
\end{abstract}

Palavras-chave: Via chilena ao socialismo, oposição popular, teoria dos movimentos sociais.

Los dilemas históricos que plantea la Unidad Popular para los investigadores del Chile contemporáneo también ofrecen la posibilidad de reconstruir fenómenos muy variados y disímiles entre sí, ensanchando con ello los giros interpretativos con que periódicamente se busca entender la experiencia socialista chilena.

Sabemos que algunos de los enfoques predominantes, como el tema político-institucional, han sido largamente trabajados por historiadores y politólogos, tanto nacionales como extranjeros. Algunos de estos trabajos se han constituido en marcos de referencia ineludibles para quienes desean conocer las dinámicas más agudas y existenciales de la Unidad Popular (Valenzuela, 1989; Garretón y Moulian, 1993). En términos generales, estos trabajos han alcanzado una amplia reputación dentro del mundo académico, pero también dentro de la elite dirigente, cuyo accionar, junto al de otros actores, fue el responsable en la construcción de un discurso y una memoria oficial sobre la crisis social y política de $1973 .{ }^{2}$

A pesar de ello, en los últimos veinte años han surgido nuevas propuestas conceptuales y temáticas en torno al tema, contribuyendo de este modo a ampliar los marcos discursivos e interpretativos (Rolle, 2003; Winn, 2004; Power, 2008; Rojas, 2009; Tinsman, 2009). No se trata por cierto de trabajos

2 Uno de los textos en donde quedó plasmada buena parte de esta memoria oficial sobre la tragedia ocurrida en 1973 y los años siguientes es el Informe de la Comisión Nacional de Verdad y Reconciliación (1991) realizado en el transcurso del primer año de gobierno de Patricio Aylwin. 
que busquen explicaciones omnicomprensivas del periodo a fin de 'competir' con aquellas propuestas que, según señalamos arriba, se habían constituido como parte esencial de los discursos oficiales. Estos nuevos trabajos transitaron, más bien, por el camino de la innovación y el rescate de sujetos y coyunturas que tuvieron su propia historia dentro de la Unidad Popular.

Considerando estas nuevas perspectivas de análisis, el tema de los sectores populares durante la UP, ha tenido, sin embargo, un desarrollo desigual. Desde ya cabría señalar que se trata de un tópico en permanente construcción, sobre todo por la carencia de lineamientos teóricos que acompañen una reflexión más profunda sobre el tema. De hecho, las dificultades para definir conceptualmente qué es lo popular resultaron un problema no tan sólo para los investigadores, sino también para los partidos y movimientos políticos que, en esos años, dirigieron una parte de sus formulaciones programáticas hacia ese sector.

Considerando tales deficiencias, este artículo busca, en primer lugar, problematizar sobre el carácter que han tenido los trabajos académicos que han abordado el tema de lo popular. Ello plantea no sólo una discusión en torno a cómo los historiadores han trabajado el concepto, sino que también, en cómo la clase política, en este caso fundamentalmente la izquierda, ha abordado este tópico. Creemos que desde la academia y las elites dirigentes se ha mirado al mundo popular como un todo homogéneo; con dinámicas y prácticas internas claramente identificables y posibles de conceptualizar. Si a ello agregamos el componente político en torno a las definiciones electorales de este mundo, es decir, con qué sectores ideológicos sentiría más "afinidad" lo popular, las conclusiones, por parte de cientistas sociales y dirigentes políticos, suelen ser más bien uniformes. La realidad material de estos sectores y el discurso histórico que la izquierda elaboró sobre la desigualdad y la pobreza, contribuyeron a afianzar la idea de que lo popular ha apoyado masiva y homogéneamente a dicho sector. En sentido inverso, se pensaba que el único actor político con un discurso específico hacia el mundo popular, y por ende altamente interpelante para el mismo, fue la izquierda. A lo largo de estas páginas, se comentan y discuten algunas de estas ideas, enfatizando en sus limitaciones y deficiencias para comprender la complejidad del mundo popular.

En una segunda parte, este artículo propone una reconstrucción y análisis de los dos principales elementos que permiten acercarse al fenómeno de los sectores populares opositores al gobierno de Allende. Estos se encuentran consignados, en primer lugar, por el análisis comparativo de algunas cifras electorales del periodo, ejercicio que permitió reconstruir la votación del centro democratacristiano y la derecha nacionalista en zonas eminentemente populares. Sorprendentemente, la votación de estos sectores logró, en marzo de 1973, penetrar en diversas zonas populares del gran Santiago, desvirtuan- 
do de este modo la tesis de que ambos partidos sólo representaban y eran apoyados por las clases medias y la burguesía. Inclusive, la votación de Jorge Alessandri y Radomiro Tomic en los comicios presidenciales de 1970 no dejó de ser significativa dentro del campo popular.

El segundo elemento está determinado por la identificación de importantes segmentos poblacionales, y por ende populares, con figuras políticas ajenas a la izquierda. El caso paradigmático a este respecto fue el de Eduardo Frei Montalva, cuyo liderazgo y carisma generaron una receptividad no menor en miles de pobladores, articulándose, entre mediados de los sesenta y el gobierno de la UP, un caso que hemos de denominar como freísmo popular. Se trata de un fenómeno bastante particular y en general poco estudiado.

La importancia de este hecho radica, para los objetivos de este estudio, en las posiciones que asumirán aquellos pobladores que se identificaban con Frei cuando éste se constituía en uno de los más férreos opositores al gobierno de Allende. Preliminarmente cabría señalar que una parte sustancial de la oposición popular a la UP se configuró gracias a la acción y dinamismo que este tipo de figuras tuvo en aquellos años. Algo similar a lo ocurrido con Frei, aunque en menor escala, parece haber sucedido con Jorge Alessandri, sin embargo, su caso resulta más difícil de pesquisar desde el punto de vista historiográfico.

Se trata, pues, de elementos preliminares que buscan abrir el debate sobre una realidad poco estudiada, pero que, no obstante, arroja luces importantes a la hora de reconstruir una parte las experiencias vividas bajo la UP.

\section{Abordajes conceptuales sobre lo popular: problemas y deficiencias}

La renovación de los estudios historiográficos en los últimos treinta años permitió ampliar las discusiones teóricas sobre el carácter, orientación y metodologías con que esta disciplina elaboraba su trabajo y proyectaba su propio devenir. A partir de estas discusiones y de la renovación en los métodos y utillajes con que trabajaba el historiador, nuevos sujetos y nuevas experiencias ingresaron al campo de la historiografía. Para Peter Burke (1993) se trató de una transformación mayor de nuestra disciplina, situación que se vio reflejada en la eclosión de nuevas historias que, ya sea desde el ámbito político o social, marcaban un distanciamiento progresivo con respecto a esa "vieja historia", a veces tan mecanicista y uniforme para reconstruir el pasado.

Esta renovación coincidió, por cierto, con los grandes cambios mundiales que comenzaban a verificarse hacia la década de los setenta. Para entonces, la crisis de las grandes utopías, por ejemplo, no era un fenómeno adscrito 
únicamente al campo de las ideas. Existían problemas materiales concretos y dinámicas sociales de mayor complejidad. En este marco, las explicaciones omnicomprensivas ya no resultaban del todo viables para desentrañar los dilemas de la sociedad post-industrial. Las rígidas estructuras sociales de algunos países daban cuenta de nuevos actores, los cuales alcanzarían un protagonismo inédito en las próximas décadas.

De todo ello, en fin, tomaría nota la historiografía. Aunque a decir verdad, se trató de discusiones que provenían desde ciertos sectores de la intelectualidad, o mejor dicho, desde áreas temáticas bastante específicas. La historia social fue uno de estos espacios. Desde allí se reelaborarían los métodos y conceptos con que tradicionalmente se había mirado la sociedad, sobre todo en el transcurso del siglo XX. Dichos elementos enfatizaban -en parte gracias a la influencia del marxismo- en las dinámicas desarrolladas fundamentalmente al interior del mundo proletario, situando, además, a los sujetos sociales dentro de estructuras y sistemas predeterminados. La crisis que supuso esta interpretación mecánica y parcial de la realidad social permitió, entre otras cosas, la emergencia de nuevos sujetos de estudio. Mujeres, niños, jóvenes y pobladores, comenzaron a hacerse un lugar, en plena década del setenta, dentro de los estudios historiográficos.

En Chile, una de las figuras pioneras a este respecto fue Gabriel Salazar. Su principal aporte consistió en abrir una temprana discusión (ya en la primera mitad de los ochenta) sobre el carácter y rol de los actores populares. Influido por las discusiones que la historiografía inglesa había tenido a este respecto, Salazar trabajó no sólo en la perspectiva de resituar el verdadero protagonismo de estos sujetos, sino también en construir un cuerpo conceptual que fuese complementario a dicha labor, o, como ha puntualizado Sofía Correa, desarrollar una suerte de "ciencia del pueblo" (2001: 48). En última instancia, y sin explicitarlo a cabalidad -al menos no en sus primeros años-, Salazar ha buscado construir una nueva interpretación de la historia de Chile, enfatizando en los vacíos y vicios de la historiografía tradicional, como una forma de subrayar el papel de quienes se sitúan en la "cara oculta de la nación". Para este investigador, dicha historiografía cumplió, dentro de su primera fase de existencia (1840-1890), con un doble y estratégico trabajo; por una parte exaltando el patriotismo independentista, y por otra, legitimando la instauración de un régimen estatal mercantil a partir de 1830 (2007: 117-118).

Como era de esperar, Salazar construyó una visión particular sobre el mundo popular. Dicho trabajo, en su conjunto, constituye un buen punto de partida para iniciar una discusión y problematización más amplia sobre el tema. En coautoría con Julio Pinto (1999), ambos historiadores dimensionaron el acontecer social de la historia contemporánea de Chile describiendo las trayectorias más significativas de los sujetos sociales de nuestro país. En el 
caso de Salazar, su punto de partida es dar cuenta del sujeto popular, dentro de sus propios espacios de desarrollo, en el contexto de la construcción estatal llevada a cabo por la elite oligárquica en Chile. Es a partir de esa experiencia, marcada entre otras cosas por la pobreza material, desde donde surgió una conciencia y una identidad particular, elementos que darían forma a lo que él ha llamado como proyecto histórico popular (1999: 95). Aunque se trata de un proyecto algo difuso, su latencia ha estado presente a lo largo del tiempo, asumiendo ritmos y temporalidades particulares que lo distinguen de los tiempos y espacios institucionales.

Esta relación tan tensa con el aparato estatal radica, en palabras de Salazar, en los efectos de la dominación patronal y oligárquica, y también por el carácter de las acciones que se desarrollan en el mundo popular (1999: 96). Bajo este escenario, la propia historicidad de los sujetos populares fue puesta en tela de juicio, tanto por el sometimiento de que fueron objeto durante el largo ciclo del peso de la noche, como también por el carácter de sus propias acciones y prácticas colectivas, las cuales no se ajustaban a las dinámicas del Estado-nación. Por ello, apunta Salazar, sus comportamientos quedan inmediatamente marginalizados, situación que se traduce en una descalificación conceptual -es decir, negando la propia historicidad de estos sujetos-, lo que correría en paralelo a las acciones represivas del sistema portaliano (1999: 96).

A los problemas ideológico-estructurales que ha debido hacer frente el movimiento popular se suma, ya en épocas recientes, nuevos desafíos y dificultades. El principal de ellos consistió en la forma como se entendía, desde la historiografía, el mundo social y popular. Como bien señala Salazar (1999: 97), ya no era posible, a fines de los setenta, sostener que los obreros eran los únicos representantes e integrantes del espacio popular. Había nuevos actores que daban cuenta de un tejido más dinámico. Incluso, el concepto de movimiento social se "quedó corto" para definir esta realidad; se hacía urgente una nueva conceptualización que incluyera específicamente el término popular.

En una óptica similar se ubica la perspectiva de María Angélica Illanes (1994) cuando enfatiza que las movilizaciones populares deben ser reconstruidas y entendidas en el largo plazo como una verdadera antítesis del proyecto oligárquico. En otras palabras, Illanes también da cuenta de la existencia de un proyecto popular, posiblemente larvado en los espacios y dinámicas de estos actores, el que igualmente resulta difícil de pesquisar e historiar, aun cuando ella lo califique de proyecto de modernidad popular otorgándole cierta materialidad. Su nacimiento, en fin, se encontró condicionado por la reacción del pueblo frente a los intentos de marginación llevados adelante por la elite, sobreponiéndose desde entonces a las tendencias represivas y excluyentes de la clase política. 
Un par de años antes de las discusiones conceptuales y metodológicas realizadas por la historia social a comienzos de los ochenta, otras disciplinas ya habían puesto su mirada en el mundo popular. Salazar y Pinto sostienen que tanto la sociología funcionalista como la tesis de la marginalidad contribuyeron, en esa línea, a restarle historicidad al sujeto popular (1999: 100). Cómo sabemos, el funcionalismo aquilataba a los sectores populares como carentes de iniciativa y movilizados únicamente por necesidades materiales que impedían una racionalización de sus demandas. Bajo esta realidad, dichos sectores se encontraban a merced de caudillos populistas que buscaban desbancar a la oligarquía de sus posiciones de poder.

La teoría de la marginalidad, por su parte, establecía un vínculo directo entre los sectores populares y el mundo rural, pues el origen de los primeros se remontaba hacia los espacios agrícolas del valle central. Desde allí, se traspasaron una serie de elementos culturales que formaron el carácter del pueblo chileno. Se trataba fundamentalmente de costumbres conservadoras y tradicionales que fueron condicionando el modo de ser de este sector, transformándolo en una masa humana esencialmente pasiva. En ese marco se inserta la acción política del gobierno democratacristiano que buscaba, a partir del diagnóstico hecho por la teoría de la marginalidad, incorporar a estos sujetos al desarrollo nacional (Vekemans \& Venegas, 1966).

Las formas como se ha conceptualizado lo popular, según hemos visto, han diferido ostensiblemente a lo largo del tiempo. No obstante, se trata de visiones que parecen tener algo en común. A nuestro juicio la mirada global de "lo popular" es transversal a las disciplinas o corrientes que en algún momento se interesaron por estudiar este tópico. En el caso de la Nueva Historia Social chilena, ese componente global estaría encarnado en lo que sus principales exponentes han identificado como proyecto histórico popular; originado en la base social como un modelo alternativo y reactivo a los proyectos estatales que se imponían desde las élites. Para Salazar e Illanes, el pueblo constituye un todo coherente que en virtud de su propia existencia y formas particulares de sociabilidad no encuentra un punto de comunión con el resto de la sociedad. Es decir, las trayectorias de las elites y otros grupos dirigentes, si bien ocupan un espacio material común, a la larga resultan disímiles y en ocasiones refractarias a los intereses del pueblo. En otras palabras, el proyecto histórico popular respondería a directrices materiales y culturales bastante específicas y autónomas ( ¿y excluyentes tal vez?) con respecto a otros sujetos y dinámicas que también forman parte de la sociedad.

Sin decirlo explícitamente, estos autores sobrevaloran el proyecto popular en desmedro de otras iniciativas, pues lo dimensionan como un conjunto conceptual y materialmente acabado que al no estar sujeto a las reglas institucionales ni a intereses económicos de corte capitalista sería más auténtico 
y legítimo. Inclusive, según apunta Salazar, los hechos históricos del mundo popular tendrían más tejido y densidad humana que los hechos normativos de la gobernabilidad (2003: 165). Es decir, lo popular en su conjunto parece situarse en una posición de privilegio con respecto a otros grupos, condensando en su interior mayores dosis de historicidad y por ende experiencias más significativas de abordar para el historiador.

El problema general de este tipo de visiones radica en su concepción global y homogeneizante de lo popular. Desde ya le asigna la virtud de poder construir un proyecto alternativo a los que hegemónicamente se impusieron a lo largo de la historia nacional, situándose casi siempre en un estatus larvario sin posibilidad de desplegarse a plenitud. La dificultad estriba en cómo podemos reconstruir dicho proyecto y cómo interpretar históricamente sus objetivos, dinámicas y cursos de acción. Se trata de un problema no menor para el oficio del historiador, pues su propio utillaje material y conceptual se vería puesto a prueba en función de las fuentes y registros que sobre dicho tópico existen. Por lo demás conviene reflexionar si acaso todas las expresiones de descontento y oposición al aparataje institucional, provenientes desde el mundo popular, trasuntaron un carácter verdaderamente proyectual que pudiera constituirse, en distintas coyunturas, en una alternativa válida a los modelos estatales. La pregunta a este respecto parece ser si la historia republicana de Chile ha sido acaso una lucha dialéctica entre dos proyectos excluyentes entre sí; uno, impuesto por las elites dirigentes desde el Estado y otro de corte popular, imaginado y materializado desde la base social y en pugna permanente con el primero.

Del mismo modo, cabe interrogarse si fue el amplio espectro que conforma lo popular el que participó en la construcción de dicho proyecto, o bien, hubo voces críticas que no se sumaron a estos intentos y buscaron más bien amoldarse a los cánones que impusieron las elites dirigentes a partir de una subsistencia consentida. El escudriñar en estos sujetos y prácticas acomodaticias supone alterar la cosmovisión que sobre lo popular tienen algunos historiadores y que indefectiblemente ha significado una mirada globalizante del fenómeno sin atender a las excepciones ni complejidades que puedan existir. Además, resulta discutible que se hable siempre de un proyecto social-popular y no de proyectos (en plural), es decir, que bajo la complejidad de las relaciones sociales bien pudieron surgir diferentes modelos y esquemas de desarrollo alternativo, los cuales podrían, incluso, haber sido contradictorios entre sí.

La discusión en torno a la forma como la Nueva Historia Social ha dimensionado lo popular no es en todo caso reciente. Por cierto este artículo no pretende arrogarse la exclusividad de un debate que ya lleva varias décadas, sino más bien reconstruir y sintetizar algunos de sus hitos más sobresalientes. A fines de los noventa se suscitó una intensa polémica entre algunos historiadores a propósito de la publicación de la Historia Contemporánea de Chile escrita por Gabriel Salazar y Julio Pinto. El punto de partida fue el 
comentario que sobre este texto publicara María Angélica Illanes en las páginas de El Mercurio (Cuadernos de Historia, 1999: 266-269). La respuesta provino por parte de Sergio Villalobos cuando comentó críticamente las palabras de Illanes, dejando en claro que la lectura de la obra de Salazar y Pinto, dados la abstracción y recursos narrativos allí empleados, le hacían imposible una lectura sostenida del mismo (Cuadernos de Historia, 1999: 271). Luego vinieron las respuestas y réplicas de cada uno, incorporándose a la discusión un interesante comentario de Rodrigo Ahumada (Cuadernos de Historia, 1999: 278-283).

En esa línea, el grueso de las críticas a la obra de Salazar y Pinto radica justamente en su valorización del sujeto popular como protagonista de la historia, desconociendo de este modo el rol de otros grupos y actores. Unido a ello, existe una crítica en torno a los objetivos del texto, el cual, al decir de Ahumada, responde claramente a un proyecto intelectual de corte ideológicohistoriográfico (Cuadernos de Historia, 1999: 279). En otras palabras, la orientación de Salazar y Pinto, y de aquellos que adhieren a estos énfasis, implica asumir que la interpretación de los fenómenos históricos, a fin de adecuarlos a una determinada posición política, resulta más importante que la reconstrucción y explicación de esos mismos fenómenos.

Adicionalmente conviene exponer una última interrogante sobre el mundo popular, su proyecto y los académicos que han podido dar cuenta de estos elementos. La pregunta podría sintetizarse de la siguiente manera: por qué ha sido únicamente la Nueva Historia Social la que ha podido pesquisar y dar cuenta de lo popular. ¿No resulta curioso que, en virtud de la importancia y trascendentalidad histórica que le han asignado algunos autores, ningún otro historiador se haya topado con tan importante fenómeno? ¿No será que acaso lo popular ha sido capturado epistémicamente por un grupo de investigadores que, recurriendo a categorías y narrativas extremadamente crípticas, han creído encontrar el sustrato y orientación más genuina de dicho segmento social?; una suerte de verdad revelada en donde un grupo muy reducido de especialistas conoce los códigos, comportamientos y dinámicas de este mundo.

En todo caso, y como enunciáramos más arriba, no ha sido únicamente la academia, o una parte de ella, la que ha conceptualizado, o más bien interpretado, las dinámicas del mundo popular. Desde las elites dirigentes, y particularmente desde la izquierda, se ha construido una visión, igualmente parcial, sobre los sujetos populares.

\section{Miradas político-partidistas sobre lo popular}

Las dinámicas de organización y lucha sindical de los sectores obreropopulares antecedieron en casi treinta años a los partidos políticos que más 
tarde representarían a estos segmentos desde el ámbito institucional. Las representaciones que hiciesen socialistas y comunistas sobre el mundo popular fueron, en términos generales y salvaguardando los matices de cada colectividad, bastante similares.

Tempranamente el PC estrecharía sus vínculos con el movimiento obrero, sobre todo en aquellas zonas industriales y fabriles en donde el proletariado constituía un segmento representativo de la población. La etapa formativa de este partido supuso un trabajo de base, cara a cara y buscando una proyección de alcance nacional que fuera más allá de las organizaciones sindicales que operaban en cada región. No fue un trabajo sencillo el de estos años, pues a las acciones represivas del Estado -en plena crisis social de inicios del siglo XX- se sumaron otros factores relevantes, como la estratégica acción del anarco-sindicalismo en los mismos espacios en donde el comunismo buscaba abrirse paso.

Los casi cincuenta años que median entre la fundación del PC y la llegada de la Unidad Popular al gobierno es un periodo complejo en la historia institucional de este partido (Álvarez, Samaniego \& Venegas, 2008). Para algunos autores se trata básicamente de una larga etapa en donde la izquierda, en su conjunto, unida al mundo popular, fue desarrollando y configurando su propio proyecto histórico (Garcés, 2010: 8-9).

A lo largo de este periodo, el PC logró conceptualizar lo popular, en virtud de su práctica y su propia ortodoxia, de una forma más bien ambigua. En ocasiones daba cuenta de un segmento social amplio y compacto, mientras que en otros momentos lograba matizar esa mirada. Remitámonos, por razones de espacio, a algunos documentos de la década del sesenta.

En un informe al XII Congreso del Partido verificado en marzo de 1962, su secretario general, Luis Corvalán se refiere a "las masas populares" -así en su conjunto y sin hacer mayores diferencias- "sus experiencias de lucha" y los desafíos que tiene por delante (1982: 9). Análogo parecer es posible detectar años más tarde cuando el propio Corvalán define las tareas del partido en función de sus intereses por convertirlo en el "gran destacamento de la clase obrera y del pueblo" -nuevamente mirando al pueblo como un todo compacto- (1982: 39).

Sin embargo, estas visiones homogéneas sobre el mundo popular fueron matizadas por el diagnóstico que el mismo Corvalán logra hacer en relación a algunas de las políticas sociales que ha implementado el gobierno democratacristiano de Eduardo Frei. En su informe al XIV Congreso del Partido, en noviembre de 1969, el secretario general diagnostica cómo un sector del pueblo se encontraba ilusionado por las promesas de cambio del gobierno y cómo otros sectores, igualmente pertenecientes al mundo popular, se en- 
contraban derechamente desalentados y sin ánimo de sumarse a las luchas que liderase la izquierda (1982: 50).

A pesar de estos matices, la visión predominante dentro del comunismo es ver lo popular como una masa más o menos homogénea, que se encuentra a la deriva en términos de representación política y que, por lo mismo, sería susceptible de ser manipulada por intereses políticos ajenos al ámbito de la izquierda.

La mirada del Partido Socialista, en tanto, interpretó igualmente al mundo popular como un todo homogéneo y además como una masa pasiva e informe que se encontraba a la espera de una conducción política firme y de orientación clasista. Esto último quedó reflejado notablemente en la obra de Oscar Waiss -miembro del comité central del PS-, Nacionalismo y socialismo en América Latina de 1954, en donde éste señala que la estrategia de la República Democrática de Trabajadores, elaborada por el propio partido, constituía la fórmula más adecuada para movilizar, junto a los proletarios, al resto del pueblo, a los campesinos y "a toda esa gama de grupos y subgrupos populares que son el producto de una tardía formación social y de una relativa indefinición en las fronteras de las clases" (citado en Jobet, 1971: 17, tomo II).

Una imagen similar aunque levemente matizada es posible observar unos años más tarde. A comienzos de 1964, y en el contexto del XX Congreso General del PS, esta colectividad hizo un crítico diagnóstico del gobierno de Jorge Alessandri, enfatizando asimismo que la principal tarea histórica que se planteaba el país era que las fuerzas populares "desplacen del poder a las clases reaccionarias y constituyan un gobierno democrático de trabajadores, bajo el signo del socialismo" (citado en Jobet, 1971: 96, tomo II). Se trataba por cierto de un nuevo contexto histórico, tanto nacional como mundial, en donde las clases proletarias estarían llamadas a ser los protagonistas de la revolución, siempre bajo la conducción de los partidos de izquierda.

Un énfasis similar al expresado más arriba se desprende de la declaración que el socialismo realizó con motivo de su XXII Congreso General de 1967. Allí se manifestó, por parte de la Subcomisión de Pobladores, que se debía procurar una acción coordinada de los sectores populares -a partir del rol que tendrían los militantes en sus respectivos barrios- a fin de crear una agitación permanente, agudizando la crisis de la burguesía y de la Democracia Cristiana (citado en Jobet, 1971: 139, tomo II). En otras palabras, el PS entiende que la movilización de los sectores populares, en este caso poblacionales, pasa necesariamente por la conducción y liderazgo que ejerza el partido, a través de sus dirigentes de base, en dichos sectores. 
A modo de síntesis, cabría señalar que la mirada de los principales partidos de izquierda sobre el mundo popular fue, en general, homogénea y parcial. De algún modo es posible vislumbrar que tanto para comunistas como socialistas, lo popular constituía una masa, numéricamente importante, pero que carecía de sentido y conciencia de su realidad material. En último caso, carecía de conciencia de clase. En este contexto, ambos partidos consideraron que su rol más importante consistía en organizar y conducir a estos segmentos sociales que se encontraban en un aparente estado de orfandad política. Por otra parte, los matices que logra percibir el PC con respecto a los segmentos populares que se ilusionan con las reformas del gobierno de la DC, constituyen de todos modos una interpretación que dimensiona a aquellos como actores sociales pasivos y manipulables. En la visión de ambos partidos, en fin, predomina la idea de que lo popular debe integrarse al proyecto de la izquierda, pues ésta constituye su representante más legítimo a la hora de defender sus derechos y aspiraciones más esenciales.

\section{Lo popular en la mirada de la UP}

Recorrer la extensa documentación que sobre la UP existe permite formarse una imagen macro de sus coyunturas más significativas. Las recopilaciones de documentos y discursos estratégicos realizadas en los últimos años permiten un acceso relativamente rápido al núcleo de las dinámicas y decursos políticos más importantes del periodo. En lo que respecta a la temática de lo popular es posible reconocer su enunciación y tratamiento en diversas fuentes. Desde ya están los discursos e intervenciones presidenciales de Salvador Allende, que constituyen una buena síntesis de la forma como la UP miraba lo popular. De igual modo esta temática está presente en los documentos de los partidos políticos. Algo de ello está presente también en las estéticas y gráficas que acompañaron, desde el campo visual, la experiencia socialista chilena.

Así, la mirada oficial sobre el tema tiene nuevamente como rasgo distintivo la homogeneidad para referirse a los sectores populares, advirtiéndolos, en general, como un todo compacto. En su mensaje presidencial del 21 de mayo de 1972, Salvador Allende dedica algunas líneas al mundo popular, señalando, a partir de una reconstrucción histórica, la relación entre pueblo y democracia: "Durante decenios hemos luchado contra una práctica y entendimiento de la democracia puramente formales, en que el sufragio, símbolo externo de la manifestación del poder, ocultaba una realidad enajenante de la voluntad popular" (1972: 33). A fin de combatir tal enajenación, Allende plantea que sólo la organización y concientización constituyen el resorte principal de la lucha popular. En ese sentido, el Presidente se compromete a que su gobierno: "[robustecerá] la organización del pueblo" (1972: 34). 
Los elementos arriba descritos son ciertamente importantes, aunque es preciso señalar que luego de su enunciación, Allende se remite exclusivamente al mundo de los trabajadores a partir de las coyunturas más significativas que se viven en esos momentos, por lo que el tema popular queda inconcluso en cuanto a un desarrollo conceptual o estratégico de mayor profundidad. Lo paradójico es que dicho apartado llevaba por subtítulo, precisamente, El desarrollo de la organización popular.

En la revisión de otros discursos y documentos presidenciales, es posible observar igualmente la uniformidad con que se trabaja e interpreta al mundo popular, ya sea insertándolos dentro de una trayectoria histórica específica, vinculada a las grandes luchas sociales de los pueblos latinoamericanos, o también, en virtud de su rol dentro de la experiencia socialista chilena (Quinteros, 2007).

Por su parte los documentos oficiales de la propia Unidad Popular, siempre dentro de su lógica estratégica, redundan en sus análisis totalizantes con que se aquilata lo popular. Posiblemente el documento más representativo a este respecto sea el propio Programa de gobierno de la Unidad Popular (1970). En este escrito se enfatiza notablemente en el rol de los sectores populares dentro del proceso de transformaciones que se llevarán a cabo en el país: "Las fuerzas populares y revolucionarias -señala el documento- no se han unido para luchar por la simple sustitución de un Presidente de la república por otro, sino para llevar a cabo los cambios de fondo que la situación nacional exige El triunfo popular abrirá paso así al régimen político más democrático de la historia del país" (1970: 14-15).

En tanto, el documento titulado Plataforma de Gobierno del Partido de la Unidad Popular, elaborado con vistas a las elecciones parlamentarias de marzo de 1973, evidencia énfasis análogos, aunque haciendo referencia a aspectos más específicos: "En frente está el mundo viejo: La vieja clase dominante, los monopolistas, los terratenientes, los aliados nacionales del imperialismo, los acaparadores, [que] se defienden y atacan a las clases populares." (Unidad Popular, S/F: 14). La UP, según este documento, ha logrado cohesionar en una estrategia unívoca a las masas, los partidos y el Gobierno en pos de un objetivo común que ha significado, en la práctica, enfrentarse a las clases dominantes (Unidad Popular, S/F: 43).

Las razones del porqué la UP interpreta a lo popular como un todo homogéneo son esencialmente diversas. Desde ya cabe mencionar que la mirada de la izquierda hacia dicho sector, según vimos más arriba, se estructuró a partir de nociones omnicomprensivas, derivadas de su propio sustento ideológico, que dividía a la sociedad en clases enfrentadas entre sí. A partir de este diagnóstico, las clases sociales poseían componentes específicos que le otorgaban su carácter y definición más particular. Lo popular, por ende, constituía parte únicamente de las clases explotadas. 
Por otro lado, cabe precisar que el diagnóstico anterior no sólo fue totalizante sino que además incompleto, pues nunca logró traspasar la interpretación ortodoxa con respecto a la composición de las clases sociales, a fin de analizar, en su propia complejidad, al mundo popular. Recordemos además, que en las formulaciones estratégicas de la propia UP el trabajador constituía el sujeto histórico más importante para viabilizar y conducir la construcción del socialismo en Chile, lo cual evidentemente parcializaba el debate conceptual sobre los actores que sustentarían la revolución.

\section{Puntos de tensión dentro del campo popular bajo la UP}

Hemos visto que la mirada oficialista del gobierno de Allende hacia lo popular se caracterizó por su uniformidad y creencia de que dicho sector se encontraba irrestrictamente en favor del proceso de cambios y transformaciones. En esta segunda parte busco tensionar dicha mirada a partir de diversas coyunturas y realidades que también fueron parte de las dinámicas del mundo popular en ese periodo. Me interesa centrar el análisis en algunas cifras electorales dentro de dichos espacios, como así también en la penetración que tuvieron ciertas figuras políticas, ajenas a la izquierda, las cuales resultaron altamente atractivas para un segmento significativo de pobladores.

Preliminarmente, conviene reflexionar en torno a la heterogeneidad que es posible apreciar en los sectores populares de nuestro país. Desde ya la estructuración del espacio popular -en la segunda mitad del siglo XX-se da preferentemente dentro de las poblaciones. Un número significativo de ellas surgió a partir de la acción de los propios pobladores que demandan al Estado una solución habitacional (Garcés, 2002). Como la respuesta gubernativa es lenta y burocrática, los sujetos toman la iniciativa y se movilizan en busca de terrenos que les permitan emplazar viviendas más sólidas y definitivas. En estos nuevos espacios no solo confluyó un sujeto específico que se moviliza sobre la base de necesidades materiales, sino que también converge una rica historia personal y colectiva que también define y cohesiona a lo popular. En otras palabras, lo popular se fue configurando desde muy temprano en nuestra historia, a lo largo de diversas coyunturas históricas y haciendo frente a distintos desafíos y dilemas. Bajo el marco temporal que estamos revisando, lo popular adquiere una definición más nítida y acabada dentro del área poblacional.

Al interior de este espacio existen diversas experiencias de vida y trayectorias esencialmente disímiles. Un número significativo de sujetos llega a estas poblaciones, vía toma de terrenos, con el objetivo de dejar atrás las precarias condiciones de vida que se desarrollaban en los campamentos. Se trata ciertamente del grupo más dinámico y nuclear de las 
nacientes poblaciones, el cual muchas veces contribuirá a decantar un perfil característico en estos lugares. Sin embargo, con el paso del tiempo la población va creciendo cuantitativa y cualitativamente con la llegada de nuevos sujetos.

Hacia fines de los sesenta y comienzos de los setenta las poblaciones se desarrollan material y socialmente. Cohabitan en su seno, en lo que respecta a las viviendas, procesos de autoconstrucción, mediaguas y otras viviendas de diversa calidad. El componente social también va evolucionando en un espacio en que resta casi todo por hacer. A los primeros pobladores que en su mayoría provienen del campamento, se suman habitantes que provienen de otras comunas. Algunos llegan a través de cooperativas y comités de vivienda, otros tantos, por recomendaciones de un familiar o vecino conocido, etc. En cuanto a las actividades productivas y laborales de sus habitantes, las poblaciones dan cuenta de un amplio abanico; contabilizándose no solo obreros y dueñas de casa, sino que también comerciantes, empleados públicos y particulares, técnicos asociados a grandes empresas y en menor medida algunos profesionales. Todo ello revierte, en fin, un cuadro material y social bastante heterogéneo.

Revisemos entonces, algunas dinámicas que permiten detectar y caracterizar, dentro del espacio social antes señalado, a la oposición popular al gobierno de la UP.

\section{El factor electoral dentro del mundo popular}

Considerando la diversidad y complejidad de estos sectores, resulta necesario hacer un escrutinio sobre cifras electorales verificadas en este periodo al interior de algunas zonas populares. Hemos de considerar para tales efectos, la elección presidencial de 1970 y los comicios parlamentarios de marzo de 1973, centrándonos específicamente en comunas populares del gran Santiago.

Cualquier aproximación inicial sobre este fenómeno tendería a reproducir nociones más o menos estáticas y preconcebidas sobre la distribución en los apoyos electorales de la sociedad chilena. En general, se piensa que la clase media y alta apoya per se al centro y la derecha política, mientras que los sectores proletarios y populares fijan sus apoyos hacia la izquierda. Sin embargo, las cifras no siempre corroboran tales impresiones. Por ello resulta necesario hacer un análisis más detallado de esta situación.

En las elecciones de presidenciales de 1970 la votación obtenida por los tres candidatos se distribuyó de la siguiente forma: 
Cuadro 1: Resultados de las elecciones presidenciales de 1970 en algunas comunas populares del gran Santiago (Cifras expresadas en porcentajes. Se incluye votación masculina y femenina. No se incluyen nulos ni blancos)

\begin{tabular}{|c|c|c|c|}
\hline Comuna & Allende & Alessandri & Tomic \\
\hline Barrancas & $48 \%$ & $24 \%$ & $31 \%$ \\
\hline Conchalí & $41 \%$ & $30 \%$ & $29 \%$ \\
\hline Renca & $42 \%$ & $28 \%$ & $30 \%$ \\
\hline Quinta Normal & $41 \%$ & $31 \%$ & $28 \%$ \\
\hline San Miguel & $45 \%$ & $29 \%$ & $25 \%$ \\
\hline La Cisterna & $40 \%$ & $32 \%$ & $28 \%$ \\
\hline La Granja & $49 \%$ & $25 \%$ & $23 \%$ \\
\hline
\end{tabular}

Fuente: Elaboración propia a partir de los datos entregados por Power (2008: 163)

A simple vista la votación del candidato de la UP, en comunas populares, fue significativa y contundente con respecto a las otras opciones. En algunos sectores como Barrancas y La Granja, la votación de Allende bordea el $50 \%$, mientras que en el resto no baja del $40 \%$. Con respecto a las candidaturas de Alessandri y Tomic no es posible sumar la votación de ambos como una forma de demostrar que quienes no apoyaban a Allende eran mayoría. Más bien, la votación de Tomic está expresando un apoyo manifiesto hacia los cambios estructurales que promueven tanto él como Allende. De hecho las propuestas programáticas de la izquierda y la DC tenían bastante sintonía en algunos aspectos. De este modo la votación de Alessandri debe ser aquilatada en su propio mérito. En ese sentido no deja de resultar llamativo que en algunas de estas comunas, como Quinta Normal o La Cisterna, el candidato de la derecha haya sacado más votos que su rival democratacristiano. Situación que se repite en lugares como Conchalí y San Miguel. Sólo en Barrancas es posible observar una tendencia clara a favor del democratacristiano. En términos generales, Alessandri logra ganar a Tomic en cinco de las siete comunas consignadas, situación que da cuenta de un voto consistentemente de centro-derecha, el cual, a partir de los meses siguientes, se constituirá en el núcleo basal de la votación en contra de la UP.

Vemos que sucedió en las elecciones parlamentarias de 1973: 
Cuadro 2: Resultados de las elecciones parlamentarias de 1973 en algunas comunas populares del gran Santiago (Cifras expresadas en porcentajes. Se incluye votación masculina y femenina. No se incluyen votos nulos ni blancos ni tampoco la votación de la Unión Socialista Popular, USOPO)

\begin{tabular}{|c|c|c|}
\hline Comunas & CODE & UP \\
\hline Barrancas & $41 \%$ & $58 \%$ \\
\hline Conchalí & $50 \%$ & $49 \%$ \\
\hline Renca & $50 \%$ & $49 \%$ \\
\hline Quinta Normal & $51 \%$ & $48 \%$ \\
\hline San Miguel & $47 \%$ & $50 \%$ \\
\hline La Cisterna & $53 \%$ & $46 \%$ \\
\hline La Granja & $40 \%$ & $58 \%$ \\
\hline
\end{tabular}

Fuente: Elaboración propia a partir de los datos entregados por Power (2008: 244).

En cuatro de las siete comunas consignadas la CODE, alianza que agrupaba a la DC y al Partido Nacional desde junio de 1972, alcanzó una cifra mayoritaria, aunque no del todo contundente, pues la UP se ve rezagada por variaciones que bordean un punto o punto y medio de diferencia. En comunas como La Granja y Barrancas es donde se advierte el peso mayoritario de la UP, con diferencias de casi veinte puntos a favor de esta última. La mayor diferencia a favor de la CODE se aprecia en La Cisterna, con casi 9 puntos de ventaja.

Resulta significativo constatar que en comunas como Conchalí, Renca o Quinta Normal -en donde Allende había obtenido una votación importante y porcentualmente mayor con respecto a Alessandri y Tomic- los votos se encontraban ahora del lado de la oposición. Y no se trataba de una oposición pragmática y con verdadera vocación democrática, al menos no en el grueso de sus grupos dirigentes, sino de una que se había erigido como férreo enemigo de la Vía chilena al Socialismo y que buscaba, por ende, provocar cuanto antes su derrumbe y caída.

Una mención especial dentro del fenómeno analizado tiene que ver con la propaganda electoral que los partidos desarrollaron a lo largo de esta coyuntura. En particular, conviene detenerse en los medios discursivos que utilizó la oposición para interpelar a la ciudadanía. Según veremos, se trató de recursos que no se dirigieron exclusivamente hacia las clases medias, sino que también buscaron interpelar a sectores populares que podían apoyar a la CODE y que de algún modo ya se habían expresado con antelación en favor de la centro-derecha. Posiblemente el periódico de oposición que logró penetrar con mayor eficacia dentro del mundo popular fue Tribuna. 
En su edición del primero de marzo de 1973, a tan sólo tres días de los comicios parlamentarios, se leía una vistosa propaganda de Sergio Onofre Jarpa, entonces candidato a senador por Santiago, que decía: "No basta con elegir un nuevo Congreso, Chile necesita un nuevo Gobierno" (Diario Tribuna, 1-III-1973: 3). En la misma edición antes citada, otra propaganda de Onofre Jarpa enfatizaba en el significado de su eventual triunfo senatorial: "Firme con Jarpa. Un voto más para Jarpa es un día menos para la UP" (Diario Tribuna, 1-III-1973: 7). Otro mensaje elaborado por el Partido Nacional, y dirigido claramente hacia los sectores populares, fue publicado en febrero de ese mismo año señalando: "el pueblo entiende a los nacionales porque el pueblo chileno también tiene ideas claras, lenguaje sobrio y actitudes varoniles. Por eso el pueblo que piensa está con los Candidatos Nacionales" (citado en Fermandois, 2013: 608).

La DC, en tanto, lograba mayor sintonía con los sectores populares en virtud de las políticas sociales implementadas bajo su gobierno (1964-1970). En este sentido corría con cierta ventaja en relación a los nacionales. Algunos de sus recursos propagandísticos apuntaban a un espectro amplio de la población, el que por cierto incluía al mundo popular. Un mensaje electoral del propio Frei Montalva, también candidato a senador por Santiago, resaltaba la importancia de los comicios parlamentarios de marzo próximo: "El plebiscito de marzo es la elección política más trascendental de este siglo. Falta sólo un mes! Estar con Frei significa trabajar por él, votar por él Desde mañana, súmese a la respuesta de Chile. Frei" (citado en Fermandois, 2013: 607).

Ciertamente, el factor propagandístico reviste una importancia no menor dentro del cuadro político de aquel entonces. Sobre todo si consideramos que algunos de sus mensajes se dirigían estratégicamente hacia el segmento popular, buscando de este modo activar el descontento, ya sea larvado o incipiente, que existía en dichas zonas con respecto al gobierno de la UP.

A modo de síntesis, cabría señalar que los porcentajes electorales más arriba expuestos expresan diversos matices a la hora de aquilatar las preferencias del mundo popular en materia de elecciones. No es posible sostener que la CODE haya sido mayoría absoluta en los barrios populares, pero tampoco queda en evidencia que la votación de la UP haya sido contundente en esos mismos espacios. Con seguridad podemos sostener que las estrategias y discursos de la derecha o el centro democratacristiano no fueron simplemente un espejismo en dichas zonas. En lo que respecta a la propaganda electoral, bien cabe suponer, preliminarmente, que si algunos pobladores fueron permeables a los mensajes de la oposición, lo mismo podría decirse de aquellos que lo fueron con respecto a la propaganda de la izquierda. A decir verdad, se dio un fenómeno más complejo, pues hubo pobladores que razonada y conscientemente apoyaron a uno u otro sector, ya sea por razones 
de militancia política, o bien, porque se sentían interpelados y representados por algunas colectividades y candidatos específicos.

\section{El impacto de algunas figuras públicas dentro del espacio popular}

Otro fenómeno que puede ayudarnos a entender la complejidad del mundo popular opositor dice relación con el impacto que han tenido, en dichos espacios, algunos partidos y figuras políticas ajenas a la izquierda. En particular, cabría mencionar el rol de la DC, la cual, desde fines de los cincuenta, venía trabajando conceptual y materialmente en torno a estos actores (Vekemans \& Venegas, 1966; Sepúlveda, 1996; Díaz, 2000). Diversas razones explican la acogida que tuvo este partido y alguna de sus figuras dentro del espacio popular; por una parte, se trataba de una colectividad portadora de un proyecto país que no rehusaba de los cambios estructurales que la sociedad demandaba, pero que perspectivaba dichas transformaciones a la luz de las encíclicas sociales de la Iglesia Católica y del aporte de diversos pensadores como Jacques Maritain y León Bloy. Estos últimos de enorme influencia dentro de la dirigencia de la DC.

Mirado en su conjunto, el proyecto de la Democracia Cristiana resultaba altamente atractivo para una ciudadanía ávida de cambios, pues representaba una postura progresista frente a las inquietudes del mundo contemporáneo desde una vertiente humanista y cristiana, que lo alejaba, en fin, de las posturas irreconciliables de la derecha y la izquierda. Todo lo anterior, además, debe ser entendido en un contexto de cambio epocal como fue la década del sesenta, en donde los movimientos contraculturales, el papel de la juventud, los cambios sociopolíticos e inclusive las propias reformas que se vivían al interior de la Iglesia Católica daban cuenta del carácter rupturista y transformador del periodo.

Un segundo elemento a considerar tiene que ver con el impacto y arrastre que causaron algunos dirigentes democratacristianos en el seno de la sociedad chilena. Posiblemente el que más repercusión tuvo fue Eduardo Frei Montalva, fundador y líder natural del partido por casi cuarenta años. Diversos testimonios dan cuenta de las aptitudes intelectuales de este personaje, lo que unido a las políticas de transformación y promoción social implementadas bajo su gobierno (1964-1970) calarían hondo en algunos segmentos de la población, particularmente en algunas zonas populares (Gazmuri, 2000). Tal parece que desde la primera mitad de los sesenta en adelante se fue conformando, dentro del imaginario social, un caso de freísmo popular. Quienes se sentían parte de este fenómeno, adherían a la figura y personalidad del propio primer mandatario, sobrepasando los intereses y orientaciones programáticas del partido. 
Hacia dicha vertiente transitaron, con seguridad, varios sectores populares que no adherían manifiestamente a alguna colectividad o corriente ideológica, sino más bien reconocían los valores y cualidades humanas del líder democratacristiano. Adicionalmente cabría precisar que la figura del ex Presidente logró representar y encauzar, en los momentos más difíciles de la UP, las angustias e incertidumbres de amplios sectores sociales. No fue extraño a este respecto que en las elecciones parlamentarias de marzo de 1973, Frei Montalva fuese electo senador por Santiago con la primera mayoría nacional, contabilizando casi cuatrocientos mil votos, muchos de los cuales provinieron desde el mundo popular, particularmente del espacio femenino (Fermandois, 2013: 616). Podría inferirse incluso, que la figura del ex Presidente lograba interpretar, en virtud de sus acciones y discursos, a aquellos sectores populares que sintiéndose opositores a la UP no manifestaban una adhesión explícita hacia algún partido o movimiento político en particular.

Algo similar, aunque en menor escala, podría decirse con respecto a Jorge Alessandri. Ya vimos que su votación en los sectores populares no dejó de ser significativa, superando incluso al candidato de la DC en algunas comunas. Alessandri representaba una figura en la cual se articulaban conceptos como seriedad, independencia y austeridad, lo que ciertamente resultaba llamativo para algunos pobladores. Posiblemente algunos recordaban con nostalgia su gobierno.

Del mismo modo, existe un episodio muy poco investigado sobre la coyuntura electoral de 1970 y que guarda directa relación con el ex Presidente. Al acercarse la fecha de los comicios, las tres candidaturas hicieron sus respectivos cierres de campaña. Los actos de Tomic y Allende fueron ampliamente difundidos por la prensa, en especial por la naciente cadena estatal; Televisión Nacional de Chile. Sin embargo, el acto final de Alessandri, realizado en el frontis de la Estación Mapocho, recibió una cobertura parcial y evidentemente sesgada. Al acto concurrieron miles de personas, de las más diversas clases sociales. No obstante, el canal público hizo hincapié en mostrar los espacios vacíos y únicamente a adherentes que pertenecían a los estratos socioeconómicos más altos, dando la impresión de que a Alessandri solo lo apoyaba la burguesía y los sectores pudientes. Tanto Jorge Navarrete como Guillermo Blanco, ex directivos del canal, reconocerían décadas después los errores y omisiones a este respecto (Albornoz, 2014: 151).

¿Fueron significativas algunas de estas figuras para decantar el comportamiento opositor de algunos pobladores? Posiblemente sí, sobre todo en el caso de Frei Montalva, pues no debemos olvidar que el grueso de la base militante democratacristiana, como así también sus simpatizantes, adherían espontáneamente a la figura del ex Presidente. De este modo, cuando Frei 
se definiera como un opositor acérrimo al gobierno, sus seguidores terminarían por asumir una postura similar. Y ello sería posible de observar tanto en sectores medios como también dentro del mundo popular.

A modo de síntesis, cabe precisar que los casos de adhesión popular a figuras de la centro-derecha constituyen un fenómeno muy poco estudiado por la historiografía nacional, sobre todo en lo que respecta a la segunda mitad del siglo XX. Hemos procurado trazar, en las páginas precedentes, algunos lineamientos e ideas generales sobre un tópico que podría arrojar, si se estudiase más a fondo, nuevas perspectivas de análisis a partir de las relaciones entre grupos dirigentes y clases sociales.

\section{Reflexiones finales}

Las dinámicas internas y coyunturales que se vivieron bajo la Unidad Popular no pudieron pasar desapercibidas para el conjunto del tejido social. Sobre todo aquellas que implicaron cierta complejidad dentro del espacio popular, el cual -según las miradas globalizantes de la izquierda- debía marchar disciplinadamente detrás del proyecto socialista. Sin embargo, hemos dado cuenta de realidades y fenómenos complejos que desvirtúan aquellas miradas omnicomprensivas con que se miraba lo popular. Existieron varios nudos críticos dentro de los tres años del gobierno de Allende. El problema de desabastecimiento y carestía de alimentos, por ejemplo, fue uno de los más apremiantes para los sectores medios y populares. Si bien existió una organización de base que intentó contrarrestar los efectos de esta situación, a la larga el problema persistió e inclusive recrudeció en algunas zonas.

Lo anterior, sumado a otros fenómenos como, por ejemplo, la adhesión espontánea a ciertas figuras de la oposición, vino de algún modo a entroncar con experiencias preexistentes en algunos sujetos populares, los cuales, por diversas razones, se distanciaban de la izquierda. Había, en algunos casos, una historia familiar ligada a la derecha, en otros casos se era partidario o simpatizante de la DC, y en algunos otros, se manifestaban posiciones más bien independientes. Estos actores, en virtud de las problemáticas que surgieron bajo la UP y que ésta no pudo resolver, conformarían su propio imaginario opositor a la Vía chilena al Socialismo.

En la mayoría de los casos se trató de una oposición más bien silenciosa, de puertas adentro, que no manifestaba explícitamente su rechazo al gobierno. Sin embargo, parece ser que se trataba de una oposición popular resueltamente anti UP, que se fue auto-legitimando en la medida en que se sentía pasada a llevar por las acciones del gobierno, o bien, porque simplemente sentía una distancia natural para con el proyecto socialista. 
Lo anterior implica de algún modo interpelar a la propia UP, sobre todo en virtud de sus carencias conceptuales a la hora de entender al mundo popular. Señalamos en la introducción de este trabajo que la izquierda visualizó lo popular como un todo homogéneo sin distinguir las particularidades y matices existentes dentro de este segmento, por lo que sus recursos estratégicos siempre dieron cuenta de estas limitaciones. Se pensaba asimismo, desde presupuestos eminentemente materiales, que lo popular en su conjunto, en tanto parte integrante de la clase proletaria, se cuadraría firmemente detrás del proceso de transformaciones que se llevarían a cabo. Como hemos visto eso no ocurrió, al menos no de la forma en que lo esperaba el gobierno, es decir, como una clase popular cohesionada y marchando firme a su lado. El solo análisis del factor electoral da cuenta de una realidad compleja a la hora de definir los rumbos y adhesiones de los sectores populares bajo estos años.

Conviene plantear también una reflexión en torno a las limitaciones conceptuales con que un sector de la academia ha entendido y analizado lo popular en los últimos treinta años. En este sentido queda abierta una interrogante mayor en torno a la relación entre estos cientistas sociales, su trabajo interpretativo sobre el mundo popular y la forma como la dirigencia de izquierda visualizó, bajo la UP, a estos segmentos. Podría decirse que ambas visiones de lo popular -la de la izquierda y aquella proveniente desde la academia- constituyen un discurso "desde arriba" que ha visto a dichos segmentos bajo énfasis omnicomprensivos y totalizantes, dejando poco espacio para dinámicas y fenómenos de mayor complejidad.

Como vimos, la oposición popular al gobierno de Allende responde a estas orientaciones, escondiendo en su seno una masa rica en experiencias individuales y colectivas que pueden aportar algunos datos significativos sobre nuestro pasado reciente. Sin embargo, el interés de los cientistas sociales y particularmente de aquellos dedicados a los temas socio-populares ha sido, hasta ahora, inconsistente y superficial.

\section{Referencias bibliográficas}

\section{Fuentes Primarias}

\section{a. Publicaciones oficiales}

Gobierno de Chile (1991). Informe de la Comisión Nacional de Verdad y Reconciliación. Santiago: La Nación.

Unidad Popular (1970). Programa de la Unidad Popular. Santiago: PLA. 
Unidad Popular (S/F). Plataforma de Gobierno del Partido de la Unidad Popular. Santiago: Quimantú.

\section{b. Impresos}

La lucha por la democracia económica y las libertades sociales. Del Segundo Mensaje del Presidente Allende ante el Congreso Pleno. 21 de mayo de 1972. Santiago: Quimantú.

\section{c. Prensa Periódica}

Diario Tribuna, Santiago, 1973.

\section{Fuentes Secundarias}

\section{a. Artículos}

Ahumada, R. (1999). "Saber histórico o discurso ideológico", en El Mercurio, 27/6/1999, reproducido en Cuadernos de Historia, U. de Chile, Nº19, diciembre de 1999.

Albornoz, C. (2014). "La experiencia televisiva en el tiempo de la Unidad Popular. La caldera del diablo", en Pinto, J. (ed.). Fiesta y drama. Nuevas historias de la Unidad Popular. Santiago: Lom.

Correa, S. (2001). "Historiografía chilena de fin de siglo", en Revista Chilena de Humanidades, Universidad de Chile, № 21.

Garcés, M. (2010). "La historia y la memoria popular de cara al Bicentenario", en Pastoral Popular, año 59, № 320.

Illanes, M. A. (1994). "Marginación y desmarginalización en el movimiento popular", en Proposiciones, № 24.

Illanes, M. A. (1999). "Nueva Historia de Chile", en El Mercurio, 9-V-1999, reproducido en Cuadernos de Historia, U. de Chile, №19, diciembre de 1999.

Quinteros, R. (2007). "Los sectores populares dentro de los Discursos Presidenciales de Salvador Allende", en Cyber Humanitatis, N44.

Rojas, J. (2009). "Los estudiantes secundarios durante la Unidad Popular, 19701973", en Historia, Pontificia Universidad Católica de Chile, № 42, vol. II, juliodiciembre.

Salazar, G. (2007). "Historiografía chilena siglo XXI: Transformación, responsabilidad, proyección", en Luis de Mussy (ed.), Balance Historiográfico Chileno. El orden del discurso y el giro crítico actual. Santiago: Universidad Finis Terrae. 
Vekemans, R. y Venegas, R. (1966). "Marginalidad y promoción popular", en Revista Mensaje, №149.

Villalobos, S. (1999). "Historia incompleta", en El Mercurio, 16-V-1999, reproducido en Cuadernos de Historia, U. de Chile, №19, diciembre de 1999.

\section{b. Libros}

Álvarez, R., Samaniego, A. y Venegas, H. -eds.- (2008). Fragmentos de una historia. El Partido Comunista de Chile en el siglo XX. Democratización, clandestinidad, rebelión (1921-1994). Santiago: ICAL.

Burke, P. (1993). Formas de hacer historia. Madrid: Alianza Editorial.

Corvalán, L. (1982). Tres periodos en nuestra línea revolucionaria. Berlín: Dietz Verlag.

Díaz, J. (2000). Chile: de la Falange Nacional a la Democracia Cristiana. Madrid: UNED.

Fermandois, J. (2013). La revolución inconclusa. La izquierda chilena y el gobierno de la Unidad Popular. Santiago: Centro de Estudios Públicos.

Garcés, M. (2002). Tomando su sitio. El movimiento de pobladores de Santiago, 1957-1970. Santiago: Lom.

Garretón, M. A. y Moulian, T. (1993). La Unidad Popular y el conflicto político en Chile. Santiago: CESOC-Lom.

Gazmuri, C. (2000). Eduardo Frei Montalva y su época. Santiago: Aguilar (2 vols.). Jobet, J.C. (1971). El Partido Socialista de Chile. Santiago: Prensa Latinoamericana. Power, M. (2008). La mujer de Derecha. El poder femenino y la lucha contra Salvador Allende, 1964-1973. Santiago: Centro de Investigaciones Diego Barros Arana.

Rolle, C. (2003). 1973. La vida cotidiana de un año crucial, Santiago Planeta, 2003.

Salazar, G. y Pinto, J. (1999). Historia Contemporánea de Chile Il. Actores identidad y movimiento. Santiago: Lom.

Salazar, G. (2003). La historia desde abajo y desde dentro. Santiago: Facultad de Artes U. de Chile, Lom.

Sepúlveda, A. (1996). Los años de la Patria Joven. La política chilena entre 19381970. Santiago: CESOC.

Tinsman, H. (2009). La tierra para el que la trabaja. Género, sexualidad y movimientos campesinos en la Reforma Agraria chilena, Santiago: Lom-Centro de Investigaciones Diego Barros Arana. 
Valenzuela, A. (1989). El quiebre de la democracia en Chile. Santiago: FLACSO.

Winn, P. (2004). Tejedores de la Revolución. Los trabajadores de Yarur y la vía chilena al socialismo. Santiago: Lom. 